\title{
Sildenafil Protects against Myocardial Ischemia-Reperfusion Injury Following Cardiac Arrest in a Porcine Model: Possible Role of the Renin-Angiotensin System
}

\author{
Guoxing Wang ${ }^{1,2}$, Qian Zhang ${ }^{1}$, Wei Yuan ${ }^{1}$, Junyuan $\mathrm{Wu}^{1}$ and Chunsheng $\mathrm{Li}^{1, *}$ \\ Received: 22 August 2015 ; Accepted: 3 November 2015 ; Published: 12 November 2015 \\ Academic Editor: Cesar Borlongan \\ 1 Department of Emergency Medicine, Beijing Chao-Yang Hospital, Capital Medical University, \\ $8^{\#}$ Worker's Stadium South Road, Chao-Yang District, Beijing 100020, China; \\ wangguoxing@ccmu.edu.cn (G.W.); zqian604@163.com (Q.Z.); 2000ywei@sina.com (W.Y.); \\ wu007838@sina.com (J.W.) \\ 2 Department of Emergency Medicine, Beijing Friendship Hospital, Capital Medical University, \\ 95" Yong'an Road, Xicheng District, Beijing 100050, China \\ * Correspondence: lichunsheng@ccmu.edu.cn; Tel./Fax: +86-10-8523-1051
}

\begin{abstract}
Sildenafil, a phosphodiesterase- 5 inhibitor sold as Viagra, is a cardioprotector against myocardial ischemia/reperfusion (I/R) injury. Our study explored whether sildenafil protects against I/R-induced damage in a porcine cardiac arrest and resuscitation (CAR) model via modulating the renin-angiotensin system. Male pigs were randomly divided to three groups: Sham group, Saline group, and sildenafil $(0.5 \mathrm{mg} / \mathrm{kg})$ group. Thirty min after drug infusion, ventricular fibrillation ( $8 \mathrm{~min}$ ) and cardiopulmonary resuscitation (up to $30 \mathrm{~min}$ ) was conducted in these animals. We found that sildenafil ameliorated the reduced cardiac function and improved the 24-h survival rate in this model. Sildenafil partly attenuated the increases of plasma angiotensin II (Ang II) and Ang (1-7) levels after CAR. Sildenafil also decreased apoptosis and Ang II expression in myocardium. The increases of expression of angiotensin-converting-enzyme (ACE), ACE2, Ang II type 1 receptor (AT1R), and the Ang (1-7) receptor Mas in myocardial tissue were enhanced after CAR. Sildenafil suppressed AT1R up-regulation, but had no effect on ACE, ACE2, and Mas expression. Sildenafilfurther boosted the upregulation of endothelial nitric oxide synthase (eNOS), cyclic guanosine monophosphate (cGMP) and inducible nitric oxide synthase(iNOS). Collectively, our results suggest that cardioprotection of sildenafil in CAR model is accompanied by an inhibition of Ang II-AT1R axis activation.
\end{abstract}

Keywords: sildenafil; myocardial ischemia; renin-angiotensin system; porcine model; Ang (1-7)

\section{Introduction}

Cardiac arrest (CA) is a major public health problem cause for both substantial morbidityand mortality among hospitalized patients [1]. Cardiopulmonary resuscitation (CPR) is a critical part of the management of CA. However, myocardial tissue suffers from ischemia/reperfusion (I/R) injury even after successful CPR. Therefore, post-cardiac arrest syndrome is a serious threat to patients, and understanding the underlying cellular and molecular mechanisms may help to develop strategies to treat post-resuscitation myocardial dysfunction.

Renin-angiotensin system (RAS) is one of the major hormone system regulating blood pressure [2]. The RAS is a complex endocrine, paracrine, and autocrine system with many components [2]. Angiotensin I (Ang I) is transformed to Ang II by the angiotensin-converting-enzyme 
(ACE). Ang II type 1 receptor (AT1R) is one of the major Ang II receptors. Ang (1-7), a recently described heptapeptide product of Ang I and Ang II with biological activity, is formed by ACE2. The endogenous receptor of Ang (1-7) is Mas. In the myocardial system, the Ang II-AT1R axis acts as a detrimental effector by promoting cardiac inflammation and fibrosis [3], causing myocardial cell death and apoptosis [4], whereas the Ang (1-7)-Mas cascade inhibits Ang II expression, thereby providing a cardioprotective effect [5].

Sildenafil, a potent and competitive inhibitor of phosphodiesterase-5 (PDE5) sold as Viagra, is used to treat erectile dysfunction primarily [6,7]. Sildenafil was found to improve exercise hemodynamics, oxygen uptake, heart failure, and pulmonary hypertension [8]. We and other groups have demonstrated the cardioprotection of sildenafil in animal models and human [8-14]. The major molecular mechanisms include enhancement of nitric oxide-cyclic guanosine monophosphate (cGMP) [15], ERK phosphorylation [16], protein kinase C (PKC) [17], RhoA/ROCK pathways [18], and adrenergic signaling [14]. A recent trial showed that although sildenafil failed to reduce filling pressure in patients with myocardial infarction, it produced beneficial hemodynamic effects on secondary end points in these patients, including enhancing cardiac output (CO), diastolic blood pressure and resistance of vascular vessels [19]. The cardioprotective effect of sildenafil was well-documented in local myocardial ischemic models with left coronary artery ligation [20]. However, whether sildenafil protects myocardial tissue against the stress of global ischemia has not been addressed. There are significant differences between the myocardial ischemic injury induced by coronary artery ligation and CA-resuscitation (CAR). Coronary artery ligation always induces local myocardial ischemia injury whereas CAR can induce global hypoperfusion that results in damage in other organs, such as cerebral I/R injury [21] and kidney I/R injury [22].

This work examined the effects of sildenafil infusion on the survival rate and cardiac indexes following global ischemia by inducible CA. Moreover, we firstly observed the influence of sildenafil infusion on the RAS system including plasma Ang (1-7) and Ang II levels. At last, the expression of ACE, AT1R, ACE2, and Mas in sildenafil-infused myocardial tissue were evaluated.

\section{Results}

\subsection{Sildenafil Improves Survival Rate in Pig CAR Model}

We did not detect any significant differences of baseline hemodynamic parameters in the three groups (data not shown). During the post-resuscitation, the number of defibrillation shocks in sildenafil-treated pigs was significantly less compared to saline-treated pigs ( $2.1 \pm 0.6$ vs. $4.9 \pm 1.2$, $p<0.05$, Table 1). The energy of shock and time to Restoration of Spontaneous Circulation (ROSC) in sildenafil-treated pigs was also lower compared to the values in saline-treated pigs (Table 1). At $24 \mathrm{~h}$ after ROSC, there were six surviving pigs in the Saline group, whereas there were ten surviving pigs in the sildenafil-treated group (Table 1). Figure 1 illustrated the survival curve.

Table 1. Outcome measures after post-resuscitation in sham, saline, and sildenafil-treated groups in a porcine myocardial ischemia/reperfusion (I/R) injury model.

\begin{tabular}{cccc}
\hline Outcomes & Sham $(n=8)$ & Saline $(n=12)$ & Sildenafil $(n=12)$ \\
\hline Number of shocks & 0 & $4.9 \pm 1.2^{* *}$ & $2.1 \pm 0.6^{\#, * *}$ \\
Total adrenaline dose (mg) & 0 & $1.9 \pm 0.7^{* *}$ & $0.8 \pm 0.3^{\#, * *}$ \\
Energy of shock (J) & 0 & $260.5 \pm 27.8^{* *}$ & $212.7 \pm 24.2^{\#, * *}$ \\
Time to ROSC (min) & 0 & $6 \pm 2.2^{* *}$ & $4 \pm 1.3^{* *}$ \\
Number of surviving pigs (at ROSC) & 8 & 9 & $11^{* *}$ \\
Number of surviving pigs (6-h after ROSC) & 8 & $6^{* *}$ & $10^{\#}$ \\
\hline
\end{tabular}

Values are means \pm SD or numbers $(n)$. ROSC $=$ restoration of spontaneous circulation. ${ }^{* *} p<0.01$ vs. sham, \# $p<0.05$ vs. saline. 


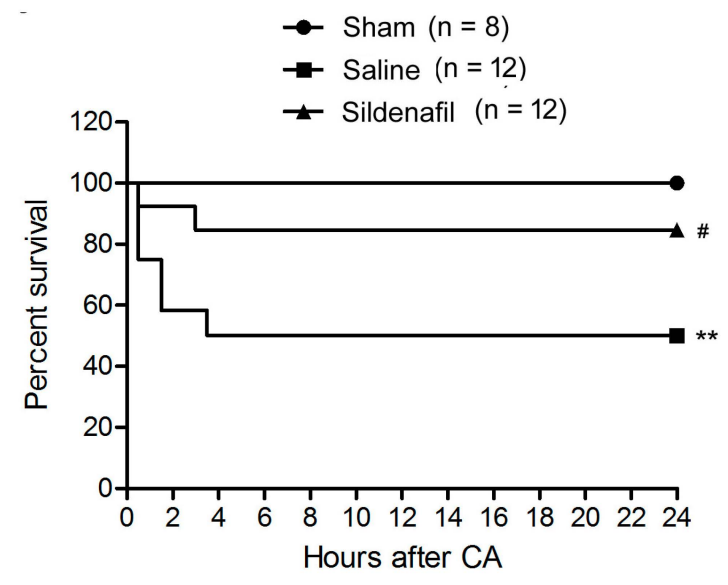

Figure 1. Survival curve of animals in the present study. ${ }^{* *} p<0.01$ vs. Sham, ${ }^{\#} p<0.05$ vs. Saline.

\subsection{Sildenafil Ameliorates the Reduced Cardiac Function in Pig CAR Model}

The HR of pigs experiencing post-resuscitation significantly increased after ROSC $(p<0.05$, Figure 2A). However, sildenafil pretreatment significantly inhibited this increase of HR (at 0.5, 2 and $4 \mathrm{~h}$ post ROSC, Figure 2A). CO was also suppressed in the Saline group, but was partly but significantly elevated by sildenafil pretreatment (at 1, 2 and 4 h post ROSC, Figure 2B). CPP was reduced by post-resuscitation, while sildenafil significantly rescued CPP (Figure 2C). CA and resuscitation boosted the MAP and sildenafil further decreased the MAP significantly at $30 \mathrm{~min}, 2 \mathrm{~h}$, and $4 \mathrm{~h}$ post ROSC (Figure 2D). These results suggest that sildenafil ameliorates the reduced cardiac function in pig CAR model.
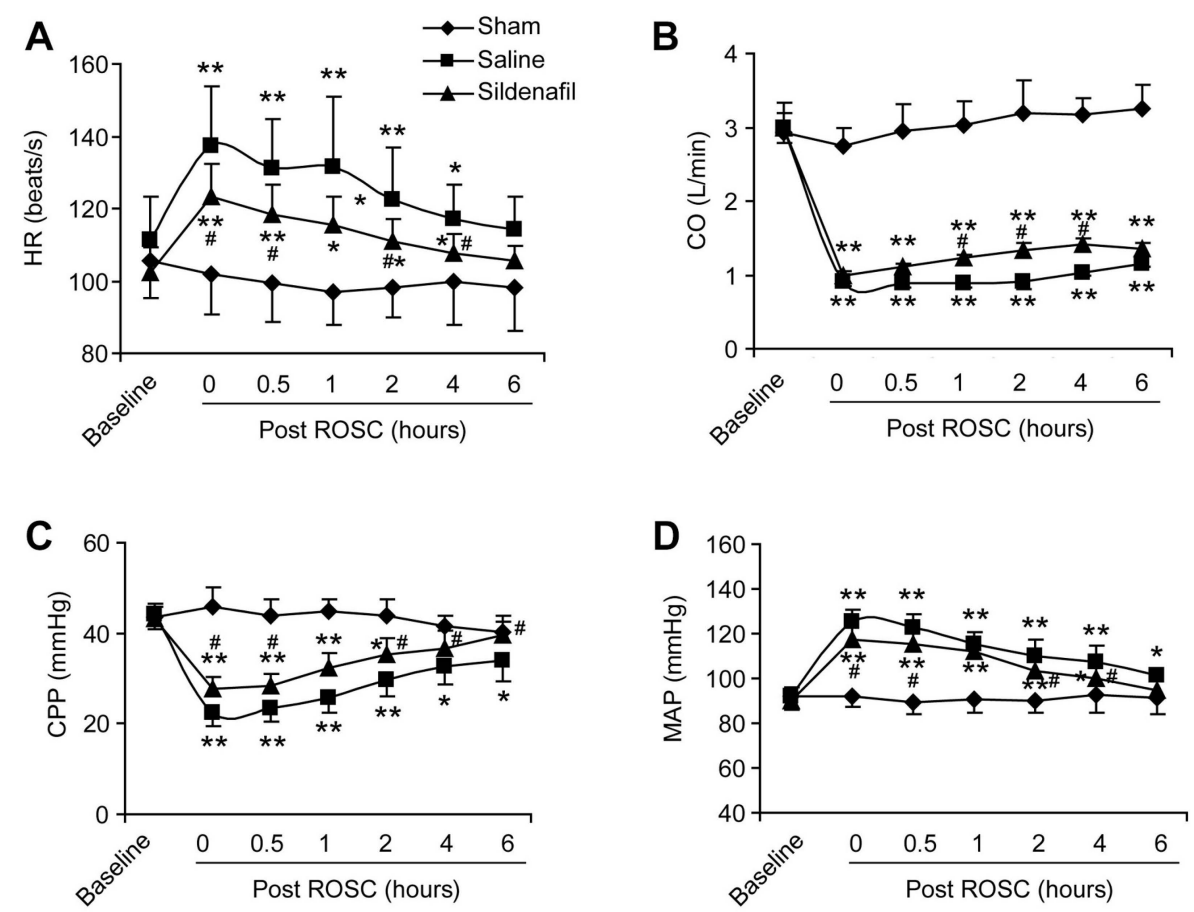

Figure 2. Cardiac functions of pigs after post-resuscitation in sham, saline, and sildenafil-treated groups. The heart rate $(\mathbf{A}) \mathrm{HR}$ (beats $/ \mathrm{s})$, cardiac output $(\mathbf{B}) \mathrm{CO}(\mathrm{L} / \mathrm{min})$, coronary perfusion pressure (C) CPP (mmHg), and mean aortic pressure (D) MAP (mmHg) were monitored at $0,0.5,1,2,4$, and $6 \mathrm{~h}$ after ROSC. ${ }^{*} p<0.05$ vs. Sham, ${ }^{* *} p<0.01$ vs. Sham, ${ }^{*} p<0.05$ vs. Saline. $n=6-10$ per group. 


\subsection{Plasma Ang II and Ang (1-7) Levels Are Decreased by Sildenafil in Pig CAR Model}

When plasma Ang II levels of pigs from the three treatment groups were examined, the Ang II levels at 4, 6 and $24 \mathrm{~h}$ post ROSC markedly increased (Figure 3A). Sildenafil pretreatment successfully reduced the upregulation of plasma Ang II compared to the Saline group. Significant sildenafil-induced reductions in Ang II levels were observed at 6 and $24 \mathrm{~h}$ post ROSC (Figure 3A). A similar result was observed for plasma Ang (1-7) levels (Figure 3B), which were elevated post-resuscitation from 1 to $24 \mathrm{~h}$ post ROSC. Elevated Ang (1-7) levels in the Saline group were partly decreased by sildenafil pretreatment. Significant sildenafil-induced reductions in Ang (1-7) serum levels were measured at 4,6 and 24 h post ROSC (Figure 3B).
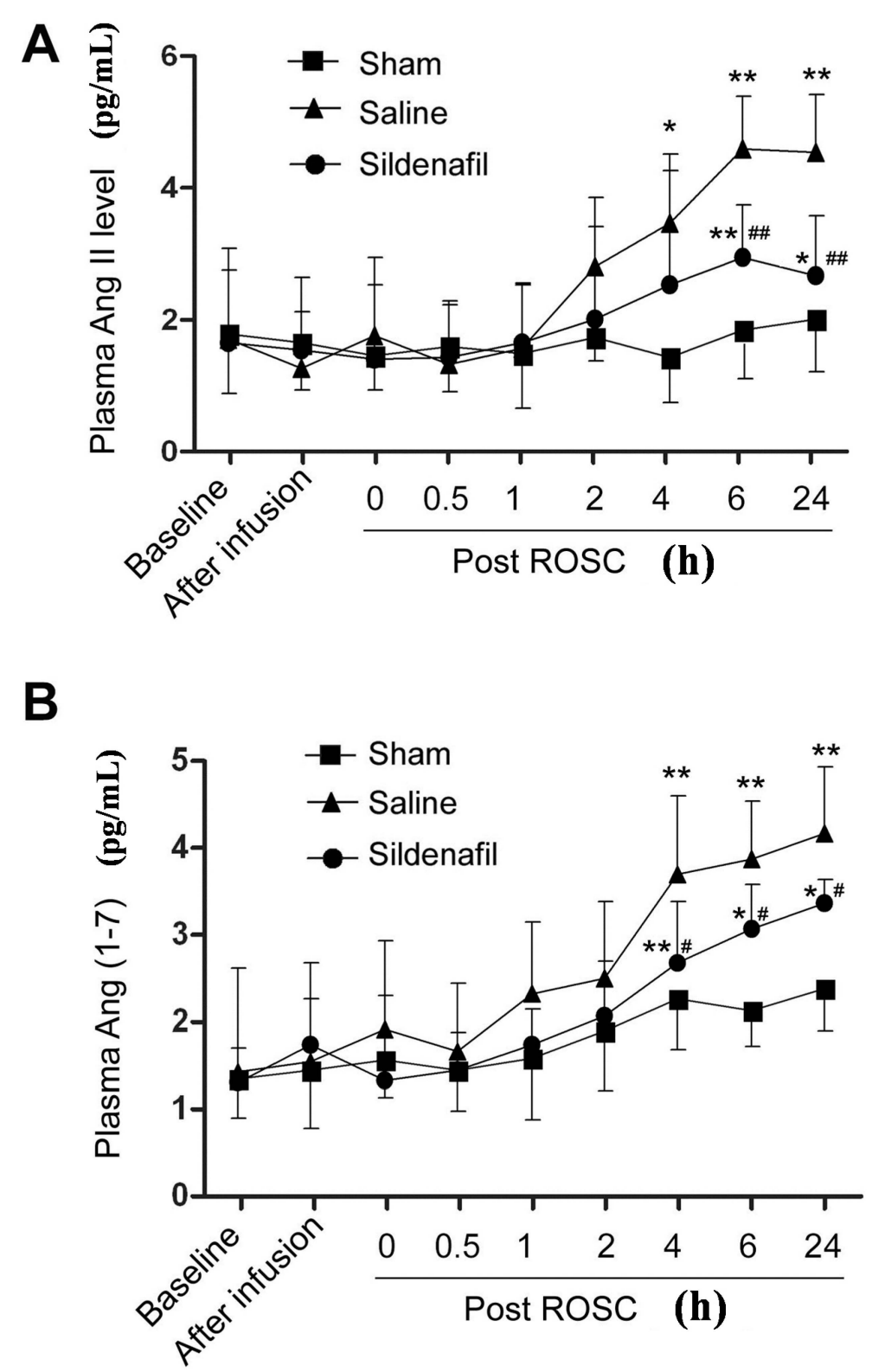

Figure 3. Plasma levels of the RAS components Ang II and Ang (1-7) in a porcine myocardial I/R injury model. ELISA determination of Ang II (A) and Ang (1-7) (B) at 0, 0.5, 1, 2, 4, 6 and $24 \mathrm{~h}$ in sham, saline, and sildenafil-treated groups following restoration of spontaneous circulation (post ROSC, h) were determined by ELISA. ${ }^{*} p<0.05$ vs. Sham, ${ }^{* *} p<0.01$ vs. Sham, ${ }^{\#} p<0.05$ vs. Saline, ${ }^{\# \#} p<0.01$ vs Saline $n=6-10$ per group. 


\subsection{Sildenafil Attenuates Myocardial Apoptosis in Pig CAR Model}

As shown in Figure 4, TUNEL assay showed that CAR injury induced remarkable apoptosis in myocardium. However, sildenafil treatment partly attenuated the myocardial apoptosis.
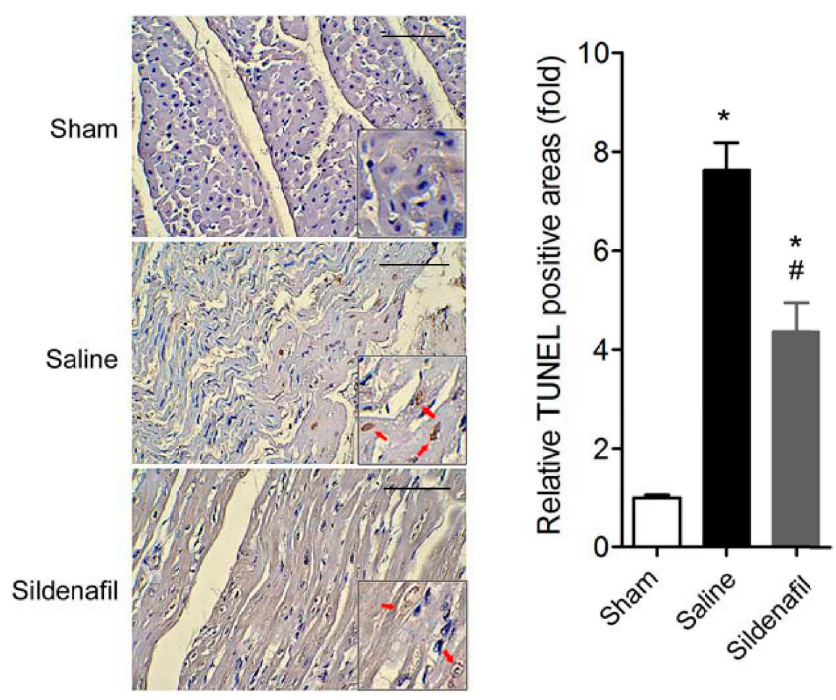

Figure 4. Myocardium apoptosis was assayed by TUNEL. Representative image and quantitative analysis of TUNEL staining on myocardium. ${ }^{*} p<0.05$ vs. Sham, ${ }^{\#} p<0.05$ vs. Saline. $n=6-10$ per group. Scale bar: $100 \mu \mathrm{m}$. The red arrows indicate the TUNEL-positive nuclei.

\subsection{Sildenafil Reduces Myocardial Ang II Expression in Pig CAR Model}

We also evaluated the myocardial Ang II expression using immunohistochemistry. As shown in Figure 5, myocardial Ang II expression was significantly increased after ROSC in this model. Sildenafil treatment partly decreased the myocardial Ang II upregulation.
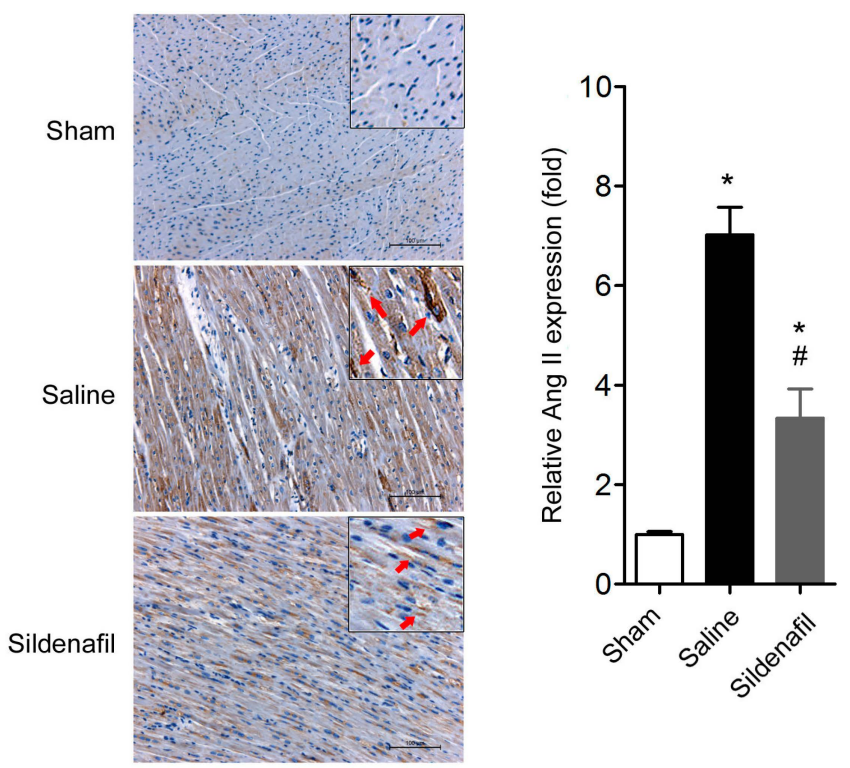

Figure 5. Myocardial Ang II expression was determined by immunohistochemistry. Representative image and quantitative analysis of Ang II immunohistochemical staining in myocardium. ${ }^{*} p<0.05$ vs. Sham, ${ }^{\#} p<0.05$ vs. Saline. $n=6-10$ per group. Scale bar: $100 \mathrm{um}$. The red arrows indicate the positive expression of Ang-II. 


\subsection{Sildenafil Does not Change ACE and ACE2 Expressions in Heart Tissue in Pig CAR Model}

Next, the expression of ACE and ACE2 proteinin the heart were studied. ACE mRNA level in pigs experiencing post-resuscitation (Saline group) were significantly higher (Figure 6A). Immunoblotting and immunohistochemistry analyses confirmed that ACE was increased on the protein level by post-resuscitation (Figure $6 \mathrm{~B}, \mathrm{C}$ ). However, there were no significant differences of cardiac ACE expression between saline and sildenafil-treated pigs (Figure 6A-C). Similarly, no differences in ACE2 mRNA (Figure 6D) and protein (Figure 6E,F) levels were observed. These data indicate that sildenafil is unable to change ACE and ACE2 protein expression in porcine heart tissue after post-resuscitation.
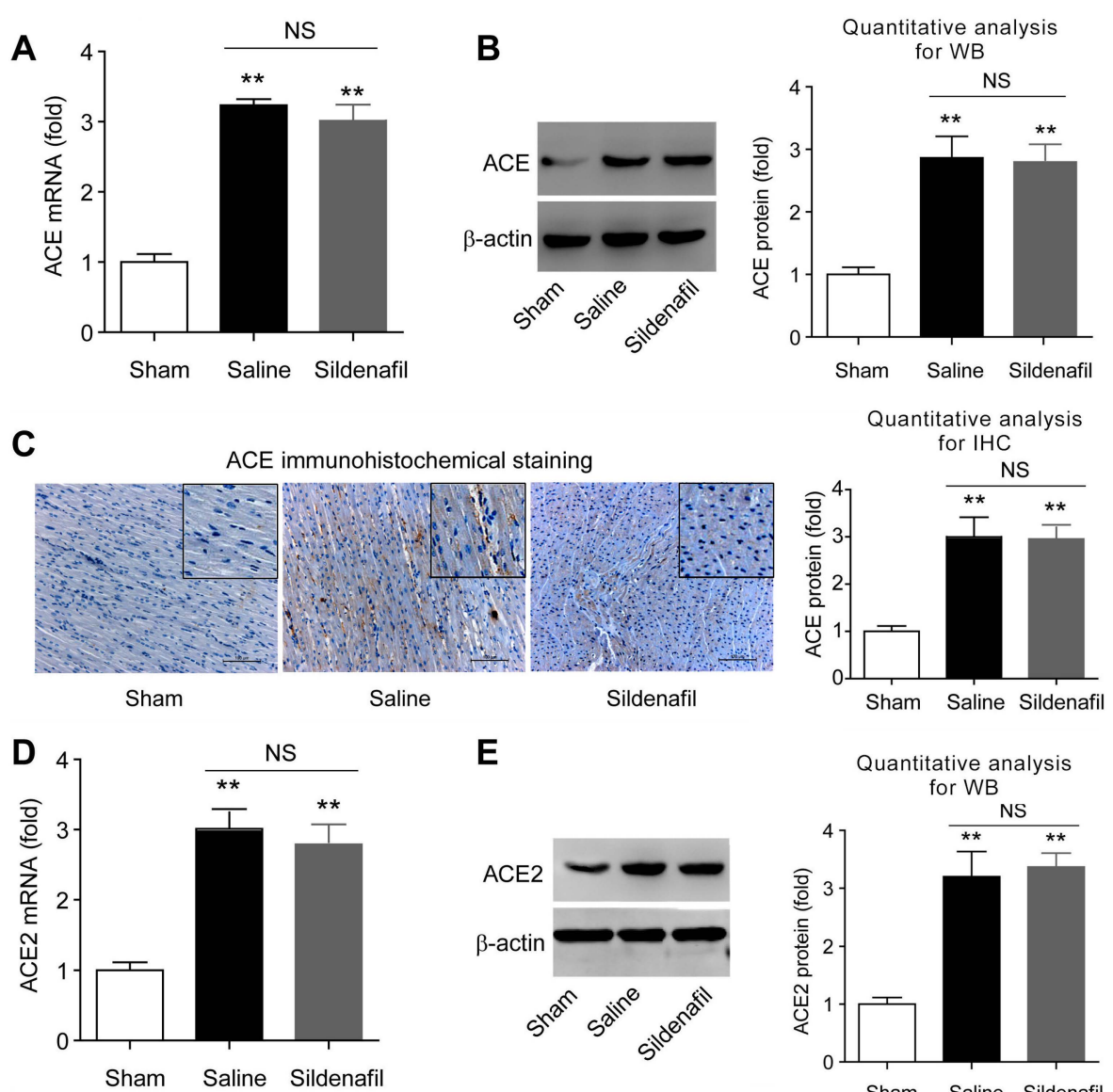

E

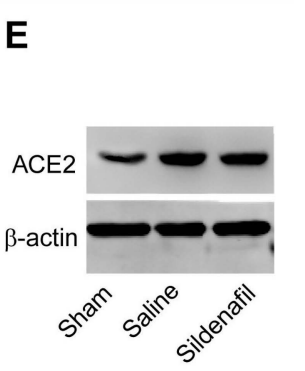

$\mathbf{F}$
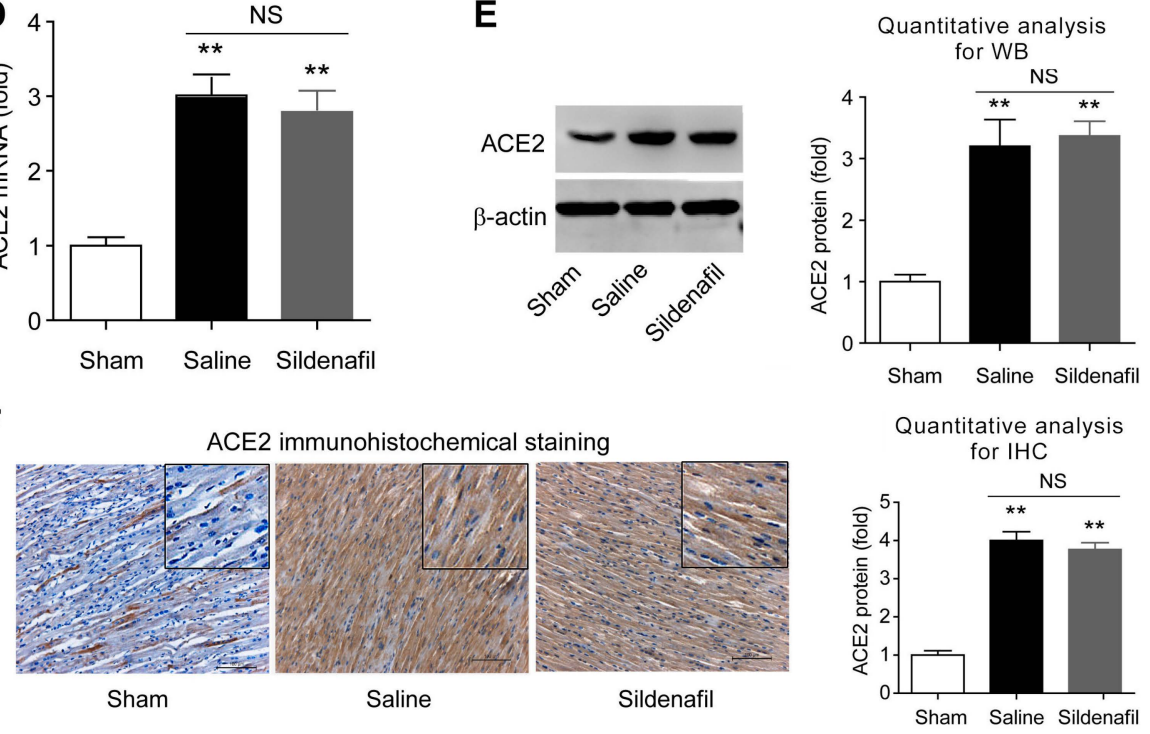

Figure 6. Tissue mRNA and protein levels of ACE and ACE2 in myocardial tissue after post-resuscitation in a porcine myocardial I/R injury model. Effects of sildenafil on ACE expression were assayed by qRT-PCR (A), Western blotting (B), and immunohistochemistry (C), and compared to the sham and saline-treated groups. ${ }^{* *} p<0.01$ vs. Sham; NS, no significance. $n=6-10$ per group. Effects of sildenafil on ACE2 expression were measured by qRT-PCR (D), Western blotting (E), and Immunohistochemistry (F), and compared to the sham and saline-treated groups. ${ }^{* *} p<0.01$ vs. Sham; NS, no significance. $n=6-10$ per group. Scale bar in C,F: $100 \mu \mathrm{m}$. 


\subsection{Sildenafil Decreases AT1R But Has no Effect on Mas Expression in Pig CAR Model}

Expression of AT1R and Mas were determined. Post-resuscitation induced AT1R mRNA (Figure 7A) and protein (Figure 7B,C) expression in myocardial tissue. Sildenafil partly, but significantly blocked these effects (Figure 7A-C). Similarly, Mas mRNA (Figure 7D) and protein (Figure 7E,F) expression were increased following post-resuscitation in myocardial tissue. However, sildenafil had no significant effect on the post-resuscitation induced Mas expression in porcine hearts (Figure 7D-F).
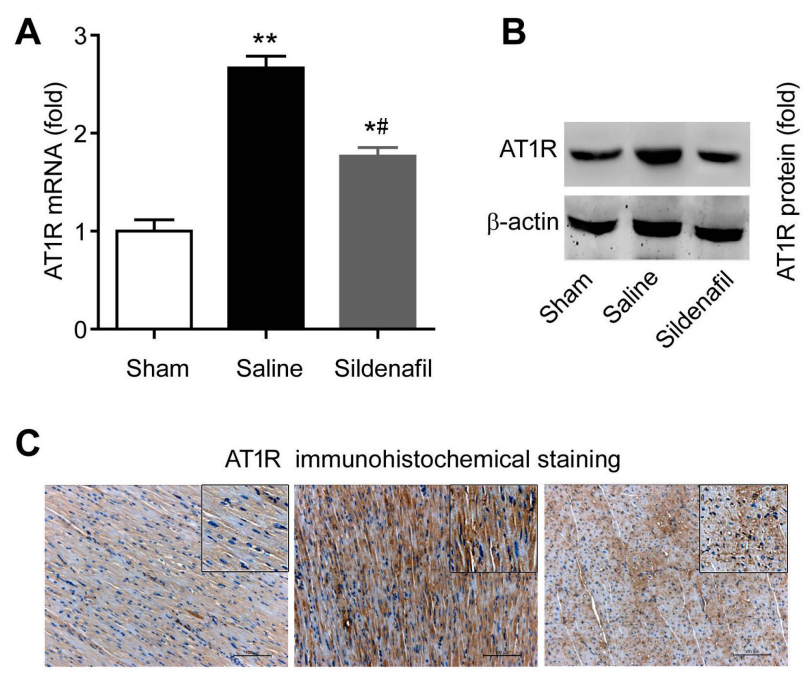

Sham

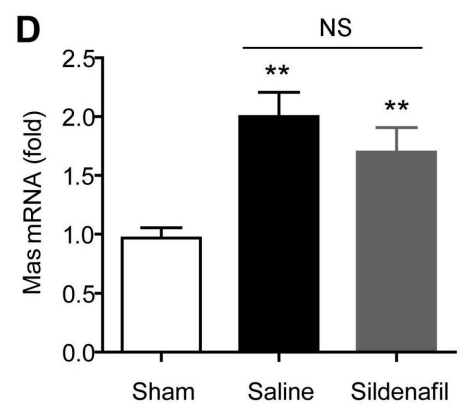

$\mathbf{F}$

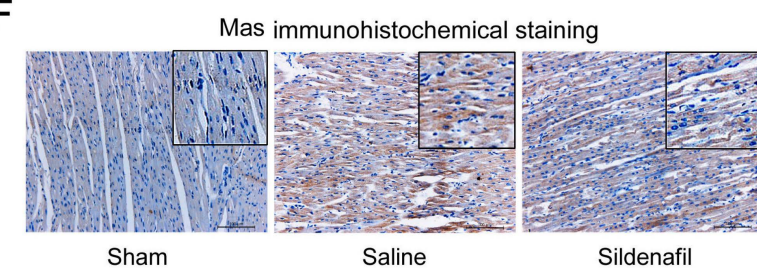

B

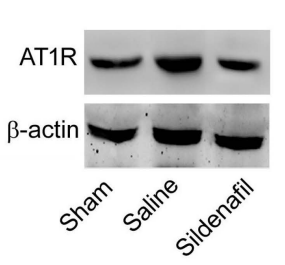

Sildenafil

E

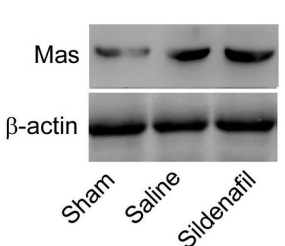

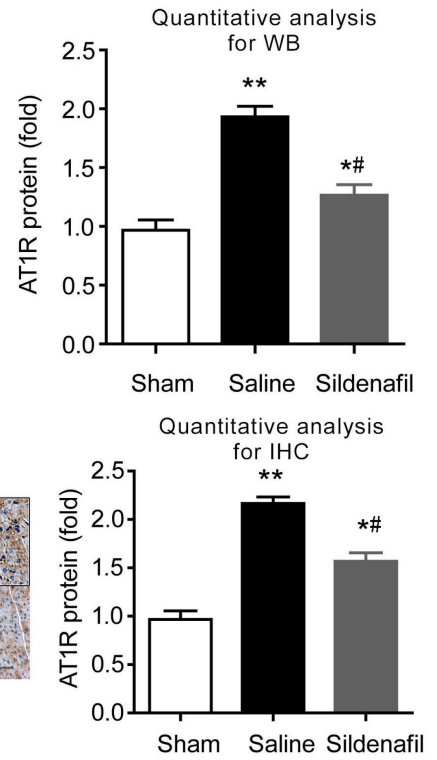

Quantitative analysis

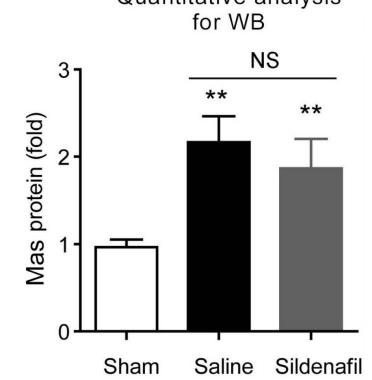

Quantitative analysis

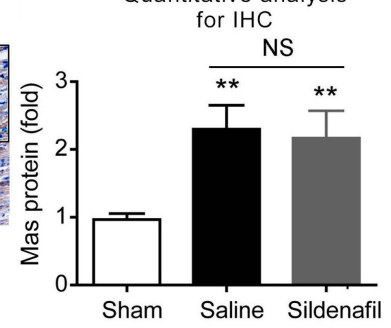

Figure 7. The expression of AT1R and Mas (mRNA and protein) after post-resuscitation in a porcine myocardial I/R injury model. Effects of sildenafil on AT1R mRNA level and protein levels were determined by qRT-PCR (A), Western blotting (B), and Immunohistochemistry (C) and compared to the sham and saline-treated groups. ${ }^{*} p<0.05$ vs. Sham, ${ }^{* *} p<0.01$ vs. Sham; ${ }^{\#} p<0.05$ vs. Saline. NS, no significance. $n=6-10$ per group. Effects of sildenafil on Mas expression were measured by qRT-PCR (D), Western blotting (E), and Immunohistochemistry (F), and compared to the sham and saline-treated groups. ${ }^{*} p<0.05$ vs. Sham, ${ }^{* *} p<0.01$ vs. Sham; ${ }^{\#} p<0.05 v s$. Saline. NS, no significance. $n=6-10$ per group. Scale bar in C,F: $100 \mu \mathrm{m}$. 


\subsection{Sildenafil Increases eNOS, iNOS and cGMP Levels in Myocardial Tissue in Pig CAR Model}

Finally, the levels of eNOS, iNOS, and cGMP in porcine myocardial tissue were measured in the myocardial I/R injury model. Levels of eNOS, iNOS, and GMP were significantly up-regulated in myocardial tissue in pig CAR model (Figure $8 \mathrm{~A}-\mathrm{C}$ ). Sildenafil pretreatment further increased eNOS, iNOS, and cGMP levels significantly in porcine myocardial tissue (Figure 8A-C).
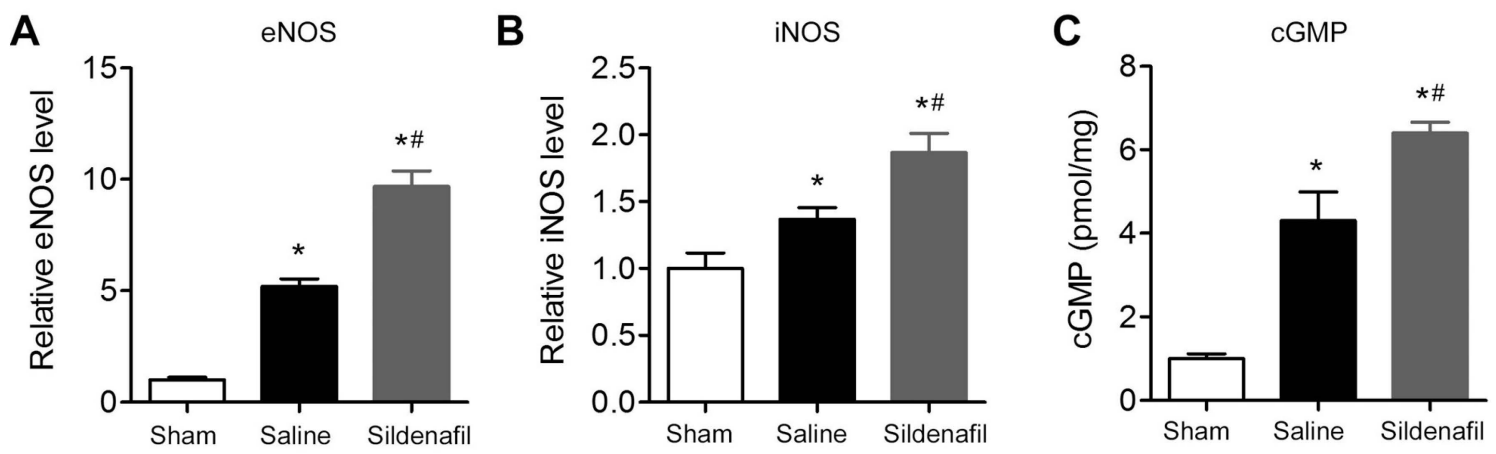

Figure 8. Effect of sildenafil on the levels of endothelial nitric oxide synthase (eNOS), inducible nitric oxide synthase (iNOS), and cyclic guanosine monophosphate (cGMP) in myocardial tissue after post-resuscitation in a porcine myocardial I/R injury model. (A) Relative eNOS levels; (B) relative iNOS levels; and (C) relative cGMP levels in myocardial tissue from sham, saline, and sildenafil-treated groups. A total of $20 \mu \mathrm{g}$ of cardiac protein homogenate was used to measure the levels of eNOS, iNOS, and cGMP by ELISA. The levels of eNOS, iNOS, and cGMP in the Sham group were set as 1 and the relative fold increase in tissue of the saline and sildenafil group was calculated, respectively. ${ }^{*} p<0.05$ vs. Sham; ${ }^{\#} p<0.05$ vs. Saline. $n=6-10$ per group.

\section{Discussion}

Erectile dysfunction in men is the original indication of sildenafil [6]. Sildenafil inhibits PDE5 to increase intracellular cGMP concentrations in the myocardium, leading to relaxation of vascular smooth cell contraction. All these events finally result in the enhancement of blood flow in tissues [6]. This hemodynamic feature prompted researchers to explore sildenafil's potential beneficial effects on the heart. The cardioprotective effects of sildenafil have been widely confirmed in various ischemic diseases $[9,16]$. Moreover, in other myocardial dysfunction, sildenafil also displayed potent cardiprotection. Isidori AM et al. [8,14] showed that a cGMP-dependent activation of PDE2 was induced by sildenafil with a pronounced cardioprotection. Giannetta, et al. [12,13] showed that sildenafil treatment improved cardiac kinetics and blood biomarkers in human with a good safety profile. In the present study, a cardioprotective role of sildenafil in post-cardiac arrest syndrome via modulating RAS was demonstrated. First, sildenafil was able to decrease the number of shocks necessary for resuscitation and it enhanced the survival rate in a porcine myocardial ischemia model induced by post-resuscitation. The cardiac function of pigs after post-resuscitation was significantly improved by sildenafil pretreatment; Second, the potential relationship between sildenafil and RAS activation during post-resuscitation was investigated. Myocardial ischemia induced by post-resuscitation remarkably increased serum Ang II and Ang (1-7) level. Post-resuscitation also elevated local expression of ACE, ACE2, AT1R, and Mas in myocardial tissue. Interestingly, sildenafil did not alter ACE, ACE2, and Mas levels in myocardial tissue, but attenuated the elevations of plasma Ang II, Ang (1-7), and myocardial AT1R expression; At last, sildenafil further increased the eNOS, iNOS and cGMP levels in myocardial tissue. All these results indicate that the modulation of the RAS cascade may contribute to the protective effect of sildenafil in post-resuscitation.

To our knowledge, this is the first in vivo study showing that sildenafil pretreatment alters RAS activation after CA, which raises the possibility that sildenafil protects myocardial I/R injury through modulating the RAS. Systemic or local RAS activation represents a critical step for chronic ventricular 
remodeling, which is an important determinant for prognosis after myocardial infarction [23]. AT1R mRNA was up-regulated 6.6-fold in myocytes from the left ventricle after myocardial infarction [24]. Inhibition of ACE or blockade of AT1R reduced apoptosis [25] and inhibited myocardial remodeling after myocardial infarction in pigs [26]. Accordingly, AT1R knockout mice with myocardial infarction displayed less myocardial remodeling and improved survival [27]. Conversely, Ang (1-7) attenuated heart failure procedure [28], while a non-peptide Mas agonist, AVE-0991, largely prevented myocardial infarction-associated heart failure [29]. These studies collectively suggested the detrimental effect of the Ang II-AT1R axis, as well as the favorable effect of the Ang (1-7)-Mas axis in the pathophysiological process after myocardial infarction. It should be noted that these effects were typically observed two or more days post myocardial infarction. Plasma Ang II and Ang (1-7) level were acutely triggered at 1-2 h post ROSC, while Ang II and Ang (1-7) level were attenuated by sildenafil pretreatment. Moreover, sildenafil inhibited the upregulation of Ang II and AT1R in myocardial tissue, but had no effect on expression of Mas, ACE, and ACE2. The elevation of Ang (1-7) might be a quick counteractive response against the enhancement of plasma Ang II and thereby exhibiting cardioprotection. Sildenafil successfully compromised the elevation of cardiac/plasma Ang II and cardiac AT1R expression, suggesting that sildenafil may partly block the detrimental effect of post-ischemic RAS activation. Unexpectedly, sildenafil pretreatment also suppressed the enhancement of plasma Ang (1-7) levels, while cardiac Mas expression was not altered by sildenafil. Although it is not known how sildenafil decreases Ang (1-7) levels, these results could rule out the possibility that Ang (1-7)-Mas cascade plays critical roles in cardioprotection of sildenafil. We, therefore, propose that sildenafil protects myocardial I/R injury via inhibiting Ang II-AT1R axis, but not by strengthening the Ang (1-7)-Mas axis. Dias et al. reported that sildenafil reduced Ang II expression in kidney rather than plasma Ang II [30]. We think this difference may be due to the discrepancy between our CAR model and their hypertensive model. Furthermore, Straubinger J et al. reported that they found higher cGMP levels in cultured cardiomyocytes and AT1R overexpression upregulated the cGMP-dependent protein kinase type I [31]. However, they also found that the progressive cardiomyocytes hypotrophy and fibrosis was not prevented by prolonged sildenafil treatment in the AT1R heart-specific transgenic mice model [31]. This discrepancy may be due to the difference between species.

The enhancement of eNOS, iNOS, and cGMP are believed to be major mechanisms of action for sildenafil [16,32] and other cardioprotectors, such as bradykinin [33]. However, this viewpoint was challenged by some investigations with opposing findings. Elrod et al. reported that utilization of sildenafil did not alter myocardial cGMP levels [34]. Recent studies have revealed additional molecules involved in the cardioprotective effect of sildenafil. These molecules include SIRT1 [35], protein kinase C [17], and phospholemman [36]. In the present study, cardiac ischemia increased eNOS, iNOS, and cGMP levels at $24 \mathrm{~h}$ post ROSC, and were further enhanced by sildenafil treatment. Furthermore, the energy required to return the pig to spontaneous circulation was much less in the sildenafil treated pigs and time to ROSC was also lower. We considered that the increased NO production by sildenafil may increase blood supply to myocardium, which thereby reduces the sympathetic tone and heart rate. So it is easier to defibrillate in the sildenafil-treated pigs. It should be noted that Garcia LA and Venneri MA demonstrated that sildenafil decreased iNOS expression in pelvic ganglia neurons and streptozotocin-induced diabetic mice model respectively $[37,38]$. We think this discrepancy might be due to the differences of experimental models. Collectively, these results support the notion that eNOS, iNOS, and cGMP elevation and the enhancement of NO production may contribute to the cardioprotection of sildenafil.

Moreover, I/R injury induces several pathophysiological changes, including reduced NO bioavailability [39], calpain activation [40] and energy status [41]. The anti-apoptosis effect of sildenafil may be another molecular mechanism for its cardioprotection. Sildenafil was reported to inhibit apoptosis and necrosis via NO signaling in cultured myocytes or in a chronic model of 
doxorubicin cardiotoxicity [11,15]. In our study, we found sildenafil attenuated TUNEL-positive cells in myocardium, supporting the anti-apoptosis action of sildenafil in myocardial I/R injury.

In fact, NO has been reported to inhibit rat aortic smooth muscle cell migration driven by Ang II via blocking AT1R [42]. Moreover, NO inhibits Ang II-induced activation of the calcium-sensitive tyrosinekinase proline-rich tyrosine kinase 2 in cardiac fibroblasts [43]. In this study, we found that sildenafil upregulated eNOS, iNOS and cGMP. We speculate that these upregulation would result in increased NO level and thereby inhibit Ang II-AT1R axis. These results raise an interesting question of how sildenafil down-regulates myocardial AT1R. Cahill et al. reported that chronic treatment of cells with a group of agents with nitric oxide (NO)-generating activity could decrease AT1R activity in dose- and time-dependent manners [44]. Another study showed that $S$-nitroso acetyl DL-penicillamine, a potent NO donor, suppressed the expression level of AT1R mRNA by $90 \%$ and AT1R number by $60 \%$ after $24 \mathrm{~h}$ of stimulation [45]. Conversely, treatment with an NO synthase inhibitor up-regulated the expression of the AT1R in an adrenal glomerulosa cell line [46]. NO was also showed to reduce AT1R protein expression in neurons [47]. However, there are controversial results on whether cGMP is important for the regulation of AT1R by NO. NO-induced down-regulation of AT1R is independent of cGMP in vascular muscle cells [46], but is cGMP-dependent in neurons [47]. Given that sildenafil is able to increase NO production through up-regulating eNOS and iNOS, it is safe to speculate that sildenafil down-regulates AT1R in the heart via inducing eNOS and iNOS. Whether cGMP participates in this effect of sildenafil needs further investigation.

In a previous work by our group [48], the major object was to investigate the action of sildenafil on apoptotic signaling pathway, microRNAs expression and nitric oxide syntheses levels. In that study, we found that sildenafil reduced TUNEL-positive cell number, enhanced the ratio of Bcl-2/Bax and prohibited activity of caspase-3 in myocardial tissues. Additionally, sildenafil treatment inhibited the increases in the microRNA-1 levels and alleviated the decreases in the microRNA-133a levels which negatively regulate pro-apoptotic genes [48]. In this study, we focused on the Ang II-AT1R axis. Sildenafil partly attenuated the increases of plasma angiotensin II (Ang II) and Ang (1-7) levels after CAR. Sildenafil also decreased apoptosis and Ang II expression and AT1R upregulation in myocardium. We considered that these results were novel compared with our previous publication [48] and may add new information on the cardioprotection of sildenafil.

There are several limitations of this study. First, in the porcine myocardial ischemia/reperfusion (I/R) injury model for CA healthy pigs were used, whereas most humans suffering from CA are not healthy. Pathophysiological dysfunction, such as hyperglycemia and hyperlipemia, always exist in individuals suffering from CA. These malfunctions may affect the outcome of sildenafil treatment in humans; Second, the inducible CA in the present study was achieved by acute VF, which may not reflect some chronic myocardial pathological changes in humans; Third, sildenafil was administrated before CA to illustrate the protective effect of sildenafil against global ischemic injury rather than limited myocardial tissue ischemia; Finally, NO inhibitors to block the increase of NO signaling were not used in this study. Whether sildenafil would still be effective in such a setting may give an answer for the requirement of NO signaling for the cardioprotection of sildenafil.

\section{Materials and Methods}

\subsection{Animals}

Inbred male landrance miniature piglets (11-13 months old, $30 \pm 2 \mathrm{~kg}$ ) were used as described previously [49]. All animals were housed in a controlled environment and fed with standard chow. All procedures were conducted in compliance with guidelines of Animal Care and Use Committee of the Capital Medical University. The experimental protocol was also approved by the Animal Experiments Committee of the Capital Medical University (permit number: 2010-D-013). 


\subsection{Experimental Procedures}

Anesthesia was achieved in the animals. Midazolam was intramuscularly injected $(0.5 \mathrm{mg} / \mathrm{kg})$ and followed with ear vein injection of propofol $(1.0 \mathrm{mg} / \mathrm{kg})$. Then, all the animals were fixed in a surgical plane of anesthesia. Sodium pentobarbital $(8 \mathrm{mg} / \mathrm{kg}$ per hour) were intravenously infused to maintain anesthesia. An endotracheal tube (cuffed 6.5- $\mathrm{mm}$ ) was inserted into trachea and a volume-controlled ventilator (Servo 900C; Siemens, Munich, Germany) was used. The tidal volume was set at $12 \mathrm{~mL} / \mathrm{kg}$ and the respiratory frequency was set at 12 breaths $/ \mathrm{min}$. An inline infrared cacographic (RespirometricInc, Murrysville, PA, USA) was used to monitor end-tidal $\mathrm{pCO}_{2}$. To maintain respiratory frequency, the end-tidal $\mathrm{pCO}_{2}$ was kept between 35 and $40 \mathrm{mmHg}$. During the procedure, acetated Ringer's solution was infused for compensating the fluid losses during the first hour of preparation. After that, acetated Ringer's solution was infused at $20 \mathrm{~mL} / \mathrm{kg}$ and glucose-electrolytes solution $(2.5 \% 8 \mathrm{~mL} / \mathrm{kg}$ per $\mathrm{h}$ ) was added.

To monitor aortic pressure and get blood samples, an angiographic catheter was inserted from the right femoral artery into the aortic arch. To monitor CO, a 7 FrSwan-Ganz catheter (Edwards Life Sciences, Irvine, CA, USA) was inserted from the right femoral vein and flow-directed into the pulmonary artery [50]. The electrocardiogram and hemodynamic parameters measured by OmniCare M1165/66A system (Hewlett Packard, Andover, MA, USA). Self-adhesive defibrillation electrodes were located on the chest wall. CPP was calculated by subtracting the right atrial from the aortic diastolic pressure.

\subsection{Experimental Myocardial I/R Injury by $C A$}

Experimental myocardial I/R injury by CA in pigs was induced as described previously [49]. The pigs were randomly divided into three groups: Sham group $(n=8)$, Saline $(0.9 \% \mathrm{NaCl})$ group $(n=12)$, and Sildenafil group $(n=12)$. Sildenafil was obtained from commercially available tablets (Viagra ${ }^{\circledR}, 25 \mathrm{mg}$ tablet, Pfizer Inc., New York, NY, USA) and dissolved with $50 \mathrm{~mL}$ saline. After the above mentioned preparations, animals were infused with the sildenafil solution $(0.5 \mathrm{mg} / \mathrm{kg})$ or the same volume saline intraperitoneally $30 \mathrm{~min}$ prior to VF and subjected with equilibration for $30 \mathrm{~min}$. Baseline measurements and blood were obtained during this time. The temporary pacemaker conductor was inserted into the right ventricle through the right internal jugular vein and connected to a GY-600A-model electrical stimulator (Kaifeng Huanan Equipment Co., Ltd., Kaifeng, China), which was used to induce ventricular fibrillation (VF). The model of electric current was set at as follows: $300 / 200 \mathrm{~ms}, 40 \mathrm{~V}, 8: 1$ proportion, $10 \mathrm{~ms}$ step length). Once VF was induced, the mean aortic pressure was rapidly decreased to zero [51]. Meanwhile, the mechanical ventilation was discontinued. External biphasic wave form defibrillation beginning at $3 \mathrm{~J} / \mathrm{kg}$ was delivered to attain ROSC 8 min later. If the initial defibrillation shock failed, energy was increased with $1 \mathrm{~J} / \mathrm{kg}$ increments. Cardiopulmonary resuscitation (CPR) was performed when the defibrillation and ROSC failed. Also, manual chest compressions were conducted at a rate of 100 compressions per minute and lasted for $2 \mathrm{~min}$. Then, another defibrillation attempt was achieved. If the first defibrillation was unsuccessful, epinephrine $(0.02 \mathrm{mg} / \mathrm{kg})$ was swiftly injected intravenously. After this, two min of CPR was performed. Ventilation was also used (compression-to-ventilation ratio, 30:2) [52]. If spontaneous circulation cannot be made, the animals would subjected with CPR for more two minutes and defibrillation was conducted once more.

We defined ROSC as the return of a palpable pulse with a systolic blood pressure of $>50 \mathrm{~mm} \mathrm{Hg}$. The animal was believed to be dead if the spontaneous circulation was not restored within $0.5 \mathrm{~h}$ [53]. The animals were ventilated with $100 \%$ oxygen after ROSC. The animals were allowed to recover from anesthesia. After that, the pigs were tightly monitored for additional $18 \mathrm{~h}$. During this period, blood samples were obtained at $0 \mathrm{~min}, 0.5,2,4$ and $6 \mathrm{~h}$ after ROSC.

During the $6 \mathrm{~h}$ intensive care period post inducible global ventricular fibrillation and cardiopulmonary resuscitation, we monitored the HR, CO, CPP and MAP in these animals hourly. We evaluate the health of pigs by Cerebral Performance Category (CPC) score [54]. If the CPC score 
$>3$, we would perform euthanasia in the animal using intravenous injection of barbiturates. In this period, three pigs in saline-treated group and 1 pig in sildenafil-treated group died due to sudden cardiac arrest. We performed standard cardiopulmonary resuscitation on these animals but failed. It should be noted that the swine Cerebral Performance Category (CPC) score [54] remained 1-2 before sudden death. None of other pigs in the three groups died during 6 to $24 \mathrm{~h}$. At last, the animals were rapidly anaesthetized by a bolus of intravenous propofol $(100 \mathrm{mg})$ and potassium chloride $(10 \%$, $10 \mathrm{~mL}$ ). The apex of left ventricular cardiac tissue was isolated, immediately frozen in liquid nitrogen and stored at $-80^{\circ} \mathrm{C}$.

\subsection{Hemodynamic Parameters}

HR, CO, CPP, and MAP at six time-points $(0,0.5,1,2,4$, and $6 \mathrm{~h})$ after ROSC were recorded. $\mathrm{MAP}$ was monitored via the right femoral arterial catheter.

\subsection{Enzyme-Linked Immunosorbent Assay (ELISA)}

The protein levels of Ang II, eNOS, and iNOS in blood plasma or cardiac tissue were measured using commercial ELISA kits (BlueGene Biotech Co., Ltd., Shanghai, China). The plasma level of Ang (1-7) was determined by an ELISA kit from BlueGene Biotech Co., Ltd. (Shanghai, China). Briefly, $50 \mu \mathrm{L}$ blood plasma or $20 \mu \mathrm{g}$ protein homogenate of cardiac tissue was added into a 96-well plate and ELISAs were performed according to the manufacturer's instructions. Cardiac tissue was homogenized with PBS plus protease inhibitor. OD values $(450 \mathrm{~nm})$ were determined in a microplate reader (Tecan M200, Munich, Germany) as previously described [55].

\subsection{Quantitative Real-Time PCR ( $q$ RT-PCR)}

The total RNA was isolated from heart tissue using Trizol (Invitrogen, Carlsbad, CA, USA) and reverse transcribed to single cDNA [56]. The cDNA was subjected to qRT-PCR with ABI 7500 system (Applied Biosystems, Foster City, CA, USA) using the following specific primers: ACE (forward: 5'-ATC AAG CGG ATC ATA AAG AAG-3', reverse: 5'-CAC GCT GTA GGT GGT TTC C-3'); ACE2 (forward: $5^{\prime}$-TCT GAA TGA CAA CAG CCT AG-3' ${ }^{\prime}$, reverse: $5^{\prime}$-CAC TCC CAT CAC AAC TCC-3'); Mas (forward: 5'-TAT TCC TCA TCT TCG CTA T-3' ${ }^{\prime}$, reverse: $5^{\prime}$-GCC CTG GTC AGA ACA ACT-3'); AT1R (forward: 5'-TCA CCT GCA TCA TCA TCT GG-3', reverse: 5'-AGC TGG TAA GAA TGA TTA GG-3'), and GAPDH (forward: 5'-GAC CCA GAA TAC CAA GTG CAG ATG TA-3'; reverse: 5'-CTG TTT CAG GAT TTA AGG TTG GAG ATT- $3^{\prime}$ ). Gene expression was normalized to GAPDH. Data analysis was performed using the $2^{-\Delta \Delta C t}$ method [57].

\subsection{Immunohistochemical Staining}

Immunohistochemical assay in heart tissue was performed as described previously [58]. Briefly, myocardial tissue sections were placed in histosol to remove the paraffin and then rehydrated in graded ethanol. After blocking in 5\% BSA for $4 \mathrm{~h}$, the sections were incubated with following primary antibodies against: ACE2 (1:200; Abcam, Cambridge, UK), ACE (1:200; Abcam), Mas (1:300; Alomone Lab, Jerusalem, Israel), and AT1R (1:200; Abcam) overnight at $4{ }^{\circ} \mathrm{C}$. After being washed with PBS solution ( $5 \mathrm{~min} \times 3$ times), sections were immersed in solutions with secondary antibodies at room temperature for $2 \mathrm{~h}$ and followed by avidin-biotin peroxidase solution incubation. Sections stained with normal rabbit serum served as negative control. After PBS washes, the color in sections were developed by diaminobenzidine tetrahydrochloride (DAB, Sigma, Milwaukee, WI, USA) and counter stained by hematoxylin. The images were captured by IX80 microscopy (Olympus, Tokyo, Japan) and analyzed with Image Pro Plus system (Carlsbad, CA, USA). More than 15 images were analyzed for every group. 


\subsection{Western Blot Analysis}

Western blot analysis was performed as described previously [59]. After harvesting heart tissue, phosphate-buffered saline (PBS, $0.1 \mathrm{mmol} / \mathrm{L}$ ) was used to wash it. Then, the tissues were homogenized with the RIPA lysis buffer plus protease inhibitors (Pierce, CA, USA). After measuring the total protein concentration with the BCA assay (Beyotime, Haimen, China), $30 \mu \mathrm{g}$ samples were run on a $10 \%-12 \%$ SDS gel. The protein was subsequently electrically transferred onto a nitrocellulose membrane and blocked using 5\% evaporated milk in PBS. Then, the membranes were incubated with primary antibodies against ACE2 (1:200), ACE (1:200), AT1R (1:300) and Mas (1:300) in TBS-plus buffer solution for $4 \mathrm{~h}$ at room temperature. After another set of rinses with PBS, membranes were incubated with HRP-conjugated secondary antibodies for $2 \mathrm{~h}$. HRP signals were detected with a chemiluminescence detection system (Amersham Biosciences, Little Chalfont Bucks, UK).

\subsection{TUNEL Assay}

To detect nuclear DNA fragmentation in apoptosis, TUNEL assay was conducted with a commercial kit (Roche Diagnostics, Mannheim, Germany) as described previously [60].

\subsection{Measurement of cGMP Levels}

A total of $100 \mathrm{mg}$ myocardial tissue from each animal was extracted in $2 \mathrm{~mL}$ RIPA lysis buffer. The homogenates were then centrifuged $(12,000 \times g, 10 \mathrm{~min})$. The supernatant was collected and aliquoted and stored at $-20{ }^{\circ} \mathrm{C}$ for cGMP determination. The cGMP levels in the extracted supernatant were assayed using commercial ELISA kit (R\&D Systems, Minneapolis, MN, USA). The average optical density was obtained using microplate reader (Tecan M200, Munich, Germany) and the values are calculated with standard curve.

\subsection{Statistical Analyses}

Results are expressed as the means \pm SD. Comparisonbetween groups was done using the Student's $t$ test or analysis of variance (ANOVA). To compare the survival rate, Chi-Square analysis was used. $p<0.05$ was considered statistically significant.

\section{Conclusions}

In summary, the administration of sildenafil improves the survival after post-resuscitation in a porcine CAR myocardial I/R injury model. We also provide the first evidence that the inhibition on Ang II-AT1R axis may contribute to the cardioprotection of sildenafil in CAR model. Our results may add a new perspective to the understanding of the cardioprotective effects of sildenafil.

Acknowledgments: This work was supported by the National Natural Science Foundation of China (No. 81374004 and No. 81372025).

Author Contributions: Guoxing Wang and Chunsheng Li conceived and designed the experiments; Guoxing Wang, Junyuan Wu and Wei Yuan perform the experiments; Qian Zhang analyzed the data; and Guoxing Wang wrote the paper.

Conflicts of Interest: The authors declare no conflict of interest.

\section{References}

1. Perkins, G.D.; Jacobs, I.G.; Nadkarni, V.M.; Berg, R.A.; Bhanji, F.; Biarent, D.; Bossaert, L.L.; Brett, S.J.; Chamberlain, D.; de Caen, A.R.; et al. Cardiac arrest and cardiopulmonary resuscitation outcome reports: Update of the utstein resuscitation registry templates for out-of-hospital cardiac arrest: A statement for healthcare professionals from a task force of the international liaison committee on resuscitation (american heart association, european resuscitation council, australian and new zealand council on resuscitation, heart and stroke foundation of canada, interamerican heart foundation, resuscitation council of southern africa, 
resuscitation council of asia); and the american heart association emergency cardiovascular care committee and the council on cardiopulmonary, critical care, perioperative and resuscitation. Circulation 2015, 132, 1286-1300. [PubMed]

2. Paul, M.; Poyan Mehr, A.; Kreutz, R. Physiology of local renin-angiotensin systems. Physiol. Rev. 2006, 86, 747-803. [CrossRef] [PubMed]

3. Diep, Q.N.; Benkirane, K.; Amiri, F.; Cohn, J.S.; Endemann, D.; Schiffrin, E.L. PPAR $\alpha$ activator fenofibrate inhibits myocardial inflammation and fibrosis in angiotensin ii-infused rats. J. Mol. Cell. Cardiol. 2004, 36, 295-304. [CrossRef] [PubMed]

4. Sovari, A.A.; Iravanian, S.; Dolmatova, E.; Jiao, Z.; Liu, H.; Zandieh, S.; Kumar, V.; Wang, K.; Bernstein, K.E.; Bonini, M.G.; et al. Inhibition of c-SRC tyrosine kinase prevents angiotensin II-mediated connexin-43 remodeling and sudden cardiac death. J. Am. Coll. Cardiol. 2011, 58, 2332-2339. [CrossRef] [PubMed]

5. Ferreira, A.J.; Santos, R.A.; Almeida, A.P. Angiotensin-(1-7): Cardioprotective effect in myocardial ischemia/reperfusion. Hypertension 2001, 38, 665-668. [CrossRef] [PubMed]

6. Goldstein, I.; Lue, T.F.; Padma-Nathan, H.; Rosen, R.C.; Steers, W.D.; Wicker, P.A. Oral sildenafil in the treatment of erectile dysfunction. N. Engl. J. Med. 1998, 338, 1397-1404. [CrossRef] [PubMed]

7. Galie, N.; Ghofrani, H.A.; Torbicki, A.; Barst, R.J.; Rubin, L.J.; Badesch, D.; Fleming, T.; Parpia, T.; Burgess, G.; Branzi, A.; et al. Sildenafil citrate therapy for pulmonary arterial hypertension. N. Engl. J. Med. 2005, 353, 2148-2157. [CrossRef] [PubMed]

8. Guazzi, M.; Vicenzi, M.; Arena, R.; Guazzi, M.D. PDE5 inhibition with sildenafil improves left ventricular diastolic function, cardiac geometry, and clinical status in patients with stable systolic heart failure: Results of a 1-year, prospective, randomized, placebo-controlled study. Circ. Heart Fail. 2011, 4, 8-17. [CrossRef] [PubMed]

9. Zhang, Q.; Yuan, W.; Wang, G.; Wu, J.; Wang, M.; Li, C. The protective effects of phosphodiesterase-5 inhibitor, sildenafil on post-resuscitation cardiac dysfunction of cardiac arrest: Metabolic evidence from microdialysis. Crit. Care 2014, 18, 641. [CrossRef] [PubMed]

10. Das, S.; Maulik, N.; Das, D.K.; Kadowitz, P.J.; Bivalacqua, T.J. Cardioprotection with sildenafil, a selective inhibitor of cyclic 3',5'-monophosphate-specific phosphodiesterase 5. Drugs Exp. Clin. Res. 2002, 28, 213-219. [PubMed]

11. Fisher, P.W.; Salloum, F.; Das, A.; Hyder, H.; Kukreja, R.C. Phosphodiesterase-5 inhibition with sildenafil attenuates cardiomyocyte apoptosis and left ventricular dysfunction in a chronic model of doxorubicin cardiotoxicity. Circulation 2005, 111, 1601-1610. [CrossRef] [PubMed]

12. Giannetta, E.; Isidori, A.M.; Galea, N.; Carbone, I.; Mandosi, E.; Vizza, C.D.; Naro, F.; Morano, S.; Fedele, F.; Lenzi, A. Chronic inhibition of cGMP phosphodiesterase 5A improves diabetic cardiomyopathy: A randomized, controlled clinical trial using magnetic resonance imaging with myocardial tagging. Circulation 2012, 125, 2323-2333. [CrossRef] [PubMed]

13. Giannetta, E.; Feola, T.; Gianfrilli, D.; Pofi, R.; Dall'Armi, V.; Badagliacca, R.; Barbagallo, F.; Lenzi, A.; Isidori, A.M. Is chronic inhibition of phosphodiesterase type 5 cardioprotective and safe? A meta-analysis of randomized controlled trials. BMC Med. 2014, 12, 185. [CrossRef] [PubMed]

14. Isidori, A.M.; Cornacchione, M.; Barbagallo, F.; di Grazia, A.; Barrios, F.; Fassina, L.; Monaco, L.; Giannetta, E.; Gianfrilli, D.; Garofalo, S.; et al. Inhibition of type 5 phosphodiesterase counteracts ß2-adrenergic signalling in beating cardiomyocytes. Cardiovasc. Res. 2015, 106, 408-420. [CrossRef] [PubMed]

15. Das, A.; Xi, L.; Kukreja, R.C. Phosphodiesterase-5 inhibitor sildenafil preconditions adult cardiac myocytes against necrosis and apoptosis. Essential role of nitric oxide signaling. J. Biol. Chem. 2005, 280, 12944-12955. [CrossRef] [PubMed]

16. Das, A.; Salloum, F.N.; Xi, L.; Rao, Y.J.; Kukreja, R.C. Erk phosphorylation mediates sildenafil-induced myocardial protection against ischemia-reperfusion injury in mice. Am. J. Physiol. Heart Circ. Physiol. 2009, 296, H1236-H1243. [CrossRef] [PubMed]

17. Das, A.; Ockaili, R.; Salloum, F.; Kukreja, R.C. Protein kinase c plays an essential role in sildenafil-induced cardioprotection in rabbits. Am. J. Physiol. Heart Circ. Physiol. 2004, 286, H1455-H1460. [CrossRef] [PubMed]

18. Fibbi, B.; Morelli, A.; Marini, M.; Zhang, X.H.; Mancina, R.; Vignozzi, L.; Filippi, S.; Chavalmane, A.; Silvestrini, E.; Colli, E.; et al. Atorvastatin but not elocalcitol increases sildenafil responsiveness in 
spontaneously hypertensive rats by regulating the RhoA/ROCK pathway. J. Androl. 2008, 29, 70-84. [CrossRef] [PubMed]

19. Andersen, M.J.; Ersboll, M.; Axelsson, A.; Gustafsson, F.; Hassager, C.; Kober, L.; Borlaug, B.A.; Boesgaard, S.; Skovgaard, L.T.; Moller, J.E. Sildenafil and diastolic dysfunction after acute myocardial infarction in patients with preserved ejection fraction: SIDAMI. Circulation 2013, 127, 1200-1208. [CrossRef] [PubMed]

20. Salloum, F.N.; Abbate, A.; Das, A.; Houser, J.E.; Mudrick, C.A.; Qureshi, I.Z.; Hoke, N.N.; Roy, S.K.; Brown, W.R.; Prabhakar, S.; et al. Sildenafil (Viagra) attenuates ischemic cardiomyopathy and improves left ventricular function in mice. Am. J. Physiol. Heart Circ. Physiol. 2008, 294, H1398-H1406. [CrossRef] [PubMed]

21. Geng, Y.; Li, E.; Mu, Q.; Zhang, Y.; Wei, X.; Li, H.; Cheng, L.; Zhang, B. Hydrogen sulfide inhalation decreases early blood-brain barrier permeability and brain edema induced by cardiac arrest and resuscitation. J. Cereb. Blood Flow Metab. 2015, 35, 494-500. [CrossRef] [PubMed]

22. Zarychanski, R.; Abou-Setta, A.M.; Turgeon, A.F.; Houston, B.L.; McIntyre, L.; Marshall, J.C.; Fergusson, D.A. Association of hydroxyethyl starch administration with mortality and acute kidney injury in critically ill patients requiring volume resuscitation: A systematic review and meta-analysis. JAMA 2013, 309, 678-688. [CrossRef] [PubMed]

23. Zreikat, H.H.; Harpe, S.E.; Slattum, P.W.; Mays, D.P.; Essah, P.A.; Cheang, K.I. Effect of renin-angiotensin system inhibition on cardiovascular events in older hypertensive patients with metabolic syndrome. Metab. Clin. Exp. 2014, 63, 392-399. [CrossRef] [PubMed]

24. Reiss, K.; Capasso, J.M.; Huang, H.E.; Meggs, L.G.; Li, P.; Anversa, P. Ang II receptors, c-myc, and c-jun in myocytes after myocardial infarction and ventricular failure. Am. J. Physiol. 1993, 264, H760-H769. [PubMed]

25. Wu, B.; Lin, R.; Dai, R.; Chen, C.; Wu, H.; Hong, M. Valsartan attenuates oxidative stress and nf-kappab activation and reduces myocardial apoptosis after ischemia and reperfusion. Eur. J. Pharmacol. 2013, 705, 140-147. [CrossRef] [PubMed]

26. Van Kats, J.P.; Duncker, D.J.; Haitsma, D.B.; Schuijt, M.P.; Niebuur, R.; Stubenitsky, R.; Boomsma, F.; Schalekamp, M.A.; Verdouw, P.D.; Danser, A.H. Angiotensin-converting enzyme inhibition and angiotensin II type 1 receptor blockade prevent cardiac remodeling in pigs after myocardial infarction: Role of tissue angiotensin II. Circulation 2000, 102, 1556-1563. [CrossRef] [PubMed]

27. Harada, K.; Sugaya, T.; Murakami, K.; Yazaki, Y.; Komuro, I. Angiotensin II type 1A receptor knockout mice display less left ventricular remodeling and improved survival after myocardial infarction. Circulation 1999, 100, 2093-2099. [CrossRef] [PubMed]

28. McMurray, J.; Davie, A.P. Angiotensin-(1-7) attenuates the development of heart failure after myocardial infarction in rats. Circulation 2002, 106, e147. [CrossRef] [PubMed]

29. Ferreira, A.J.; Jacoby, B.A.; Araujo, C.A.; Macedo, F.A.; Silva, G.A.; Almeida, A.P.; Caliari, M.V.; Santos, R.A. The nonpeptide angiotensin-(1-7) receptor Mas agonist AVE-0991 attenuates heart failure induced by myocardial infarction. Am. J. Physiol. Heart Circ. Physiol. 2007, 292, H1113-H1119. [CrossRef] [PubMed]

30. Dias, A.T.; Cintra, A.S.; Frossard, J.C.; Palomino, Z.; Casarini, D.E.; Gomes, I.B.; Balarini, C.M.; Gava, A.L.; Campagnaro, B.P.; Pereira, T.M.; et al. Inhibition of phosphodiesterase 5 restores endothelial function in renovascular hypertension. J. Transl. Med. 2014, 12, 250. [CrossRef] [PubMed]

31. Straubinger, J.; Schottle, V.; Bork, N.; Subramanian, H.; Dunnes, S.; Russwurm, M.; Gawaz, M.; Friebe, A.; Nemer, M.; Nikolaev, V.O.; et al. Sildenafil does not prevent heart hypertrophy and fibrosis induced by cardiomyocyte angiotensin II type 1 receptor signaling. J. Pharmacol. Exp. Ther. 2015, 354, 406-416. [CrossRef] [PubMed]

32. Salloum, F.; Yin, C.; Xi, L.; Kukreja, R.C. Sildenafil induces delayed preconditioning through inducible nitric oxide synthase-dependent pathway in mouse heart. Circ. Res. 2003, 92, 595-597. [CrossRef] [PubMed]

33. Oldenburg, O.; Qin, Q.; Krieg, T.; Yang, X.M.; Philipp, S.; Critz, S.D.; Cohen, M.V.; Downey, J.M. Bradykinin induces mitochondrial ROS generation via NO, cGMP, pKG, and mitoK $\mathrm{atp}_{\mathrm{p}}$ channel opening and leads to cardioprotection. Am. J. Physiol. Heart Circ. Physiol. 2004, 286, H468-H476. [CrossRef] [PubMed]

34. Elrod, J.W.; Greer, J.J.; Lefer, D.J. Sildenafil-mediated acute cardioprotection is independent of the NO/cGMP pathway. Am. J. Physiol. Heart Circ. Physiol. 2007, 292, H342-H347. [CrossRef] [PubMed] 
35. Shalwala, M.; Zhu, S.G.; Das, A.; Salloum, F.N.; Xi, L.; Kukreja, R.C. Sirtuin 1 (Sirt1) activation mediates sildenafil induced delayed cardioprotection against ischemia-reperfusion injury in mice. PLoS ONE 2014, 9, e86977. [CrossRef] [PubMed]

36. Madhani, M.; Hall, A.R.; Cuello, F.; Charles, R.L.; Burgoyne, J.R.; Fuller, W.; Hobbs, A.J.; Shattock, M.J.; Eaton, P. Phospholemman Ser69 phosphorylation contributes to sildenafil-induced cardioprotection against reperfusion injury. Am. J. Physiol. Heart Circ. Physiol. 2010, 299, H827-H836. [CrossRef] [PubMed]

37. Garcia, L.A.; Hlaing, S.M.; Gutierrez, R.A.; Sanchez, M.D.; Kovanecz, I.; Artaza, J.N.; Ferrini, M.G. Sildenafil attenuates inflammation and oxidative stress in pelvic ganglia neurons after bilateral cavernosal nerve damage. Int. J. Mol. Sci. 2014, 15, 17204-17220. [CrossRef] [PubMed]

38. Venneri, M.A.; Giannetta, E.; Panio, G.; de Gaetano, R.; Gianfrilli, D.; Pofi, R.; Masciarelli, S.; Fazi, F.; Pellegrini, M.; Lenzi, A.; et al. Chronic inhibition of pde5 limits pro-inflammatory monocyte-macrophage polarization in streptozotocin-induced diabetic mice. PLoS ONE 2015, 10, e0126580. [CrossRef] [PubMed]

39. Jung, C.; Gonon, A.T.; Sjöquist, P.-O.; Lundberg, J.O.; Pernow, J. Arginase inhibition mediates cardioprotection during ischaemia-reperfusion. Cardiovasc. Res. 2010, 85, 147-154. [CrossRef] [PubMed]

40. Sonobe, T.; Akiyama, T.; Du, C.K.; Zhan, D.Y.; Shirai, M. Contribution of calpain to myoglobin efflux from cardiomyocytes during ischaemia and after reperfusion in anaesthetized rats. Acta Physiol. 2014, 210, 823-831. [CrossRef] [PubMed]

41. Liepinsh, E.; Makrecka, M.; Kuka, J.; Makarova, E.; Vilskersts, R.; Cirule, H.; Sevostjanovs, E.; Grinberga, S.; Pugovics, O.; Dambrova, M. The heart is better protected against myocardial infarction in the fed state compared to the fasted state. Metab. Clin. Exp. 2014, 63, 127-136. [CrossRef] [PubMed]

42. Dubey, R.K.; Jackson, E.K.; Luscher, T.F. Nitric oxide inhibits angiotensin ii-induced migration of rat aortic smooth muscle cell. Role of cyclic-nucleotides and angiotensin1 receptors. J. Clin. Investig. 1995, 96, 141-149. [CrossRef] [PubMed]

43. Wang, D.; Yu, X.; Brecher, P. Nitric oxide inhibits angiotensin II-induced activation of the calcium-sensitive tyrosine kinase proline-rich tyrosine kinase 2 without affecting epidermal growth factor receptor transactivation. J. Biol. Chem. 1999, 274, 24342-24348. [CrossRef] [PubMed]

44. Cahill, P.A.; Redmond, E.M.; Foster, C.; Sitzmann, J.V. Nitric oxide regulates angiotensin II receptors in vascular smooth muscle cells. Eur. J. Pharmacol. 1995, 288, 219-229. [CrossRef]

45. Ichiki, T.; Usui, M.; Kato, M.; Funakoshi, Y.; Ito, K.; Egashira, K.; Takeshita, A. Downregulation of angiotensin II type 1 receptor gene transcription by nitric oxide. Hypertension 1998, 31, 342-348. [CrossRef] [PubMed]

46. Usui, M.; Ichiki, T.; Katoh, M.; Egashira, K.; Takeshita, A. Regulation of angiotensin II receptor expression by nitric oxide in rat adrenal gland. Hypertension 1998, 32, 527-533. [CrossRef] [PubMed]

47. Sharma, N.M.; Zheng, H.; Li, Y.F.; Patel, K.P. Nitric oxide inhibits the expression of at1 receptors in neurons. Am. J. Physiol. Cell Physiol. 2012, 302, C1162-C1173. [CrossRef] [PubMed]

48. Zhang, Q.; Wang, G.; Yuan, W.; Wu, J.; Wang, M.; Li, C. The effects of phosphodiesterase-5 inhibitor sildenafil against post-resuscitation myocardial and intestinal microcirculatory dysfunction by attenuating apoptosis and regulating micrornas expression: Essential role of nitric oxide syntheses signaling. J. Transl. Med. 2015, 13, 177. [CrossRef] [PubMed]

49. Guo, Z.J.; Li, C.S.; Yin, W.P.; Hou, X.M.; Gu, W.; Zhang, D. Comparison of shock-first strategy and cardiopulmonary resuscitation-first strategy in a porcine model of prolonged cardiac arrest. Resuscitation 2013, 84, 233-238. [CrossRef] [PubMed]

50. Wang, S.; Li, C.; Ji, X.; Yang, L.; Su, Z.; Wu, J. Effect of continuous compressions and 30:2 cardiopulmonary resuscitation on global ventilation/perfusion values during resuscitation in a porcine model. Crit. Care Med. 2010, 38, 2024-2030. [CrossRef] [PubMed]

51. Zhang, Q.; Li, C. Combination of epinephrine with esmolol attenuates post-resuscitation myocardial dysfunction in a porcine model of cardiac arrest. PLOS ONE 2013, 8, e82677. [CrossRef] [PubMed]

52. Ji, X.F.; Li, C.S.; Wang, S.; Yang, L.; Cong, L.H. Comparison of the efficacy of nifekalant and amiodarone in a porcine model of cardiac arrest. Resuscitation 2010, 81, 1031-1036. [CrossRef] [PubMed]

53. Valenzuela, T.D.; Roe, D.J.; Cretin, S.; Spaite, D.W.; Larsen, M.P. Estimating effectiveness of cardiac arrest interventions: A logistic regression survival model. Circulation 1997, 96, 3308-3313. [CrossRef] [PubMed] 
54. Kern, K.B.; Hilwig, R.W.; Berg, R.A.; Sanders, A.B.; Ewy, G.A. Importance of continuous chest compressions during cardiopulmonary resuscitation: Improved outcome during a simulated single lay-rescuer scenario. Circulation 2002, 105, 645-649. [CrossRef] [PubMed]

55. Wang, P.; Xu, T.Y.; Wei, K.; Guan, Y.F.; Wang, X.; Xu, H.; Su, D.F.; Pei, G.; Miao, C.Y. Arrb1/ $\beta$-arrestin-1 mediates neuroprotection through coordination of becn1-dependent autophagy in cerebral ischemia. Autophagy 2014, 10, 1535-1548. [CrossRef] [PubMed]

56. Wang, P.; Xu, T.Y.; Guan, Y.F.; Zhao, Y.; Li, Z.Y.; Lan, X.H.; Wang, X.; Yang, P.Y.; Kang, Z.M.; Vanhoutte, P.M.; et al. Vascular smooth muscle cell apoptosis is an early trigger for hypothyroid atherosclerosis. Cardiovasc. Res. 2014, 102, 448-459. [CrossRef] [PubMed]

57. Wang, P.; Xu, T.Y.; Guan, Y.F.; Tian, W.W.; Viollet, B.; Rui, Y.C.; Zhai, Q.W.; Su, D.F.; Miao, C.Y. Nicotinamide phosphoribosyltransferase protects against ischemic stroke through sirt1-dependent adenosine monophosphate-activated kinase pathway. Ann. Neurol. 2011, 69, 360-374. [CrossRef] [PubMed]

58. Gu, W.; Zhang, Q.; Yin, W.; Li, C. Caspase-3-mediated splenic lymphocyte apoptosis in a porcine model of cardiac arrest. Am. J. Emerg. Med. 2014, 32, 1027-1032. [CrossRef] [PubMed]

59. Wang, P.; Xu, T.Y.; Guan, Y.F.; Su, D.F.; Fan, G.R.; Miao, C.Y. Perivascular adipose tissue-derived visfatin is a vascular smooth muscle cell growth factor: Role of nicotinamide mononucleotide. Cardiovasc. Res. 2009, 81, 370-380. [CrossRef] [PubMed]

60. Wang, P.; Du, H.; Zhou, C.-C.; Song, J.; Liu, X.; Cao, X.; Mehta, J.L.; Shi, Y.; Su, D.-F.; Miao, C.-Y. Intracellular NAMPT-NAD ${ }^{+}$-SIRT1 cascade improves post-ischaemic vascular repair by modulating notch signalling in endothelial progenitors. Cardiovasc. Res. 2014, 104, 477-488. [CrossRef] [PubMed]

(C) 2015 by the authors; licensee MDPI, Basel, Switzerland. This article is an open access article distributed under the terms and conditions of the Creative Commons by Attribution (CC-BY) license (http://creativecommons.org/licenses/by/4.0/). 